The test compound was emulsified with water and the wetting agent and was sprayed in an 8 -in. diameter on top of the stalk portion of decapitated plants with a handoperated sprayer under $25 \mathrm{lb}$./in. ${ }^{2}$. The rate of application varied from greenhouse to field plants ranging from 0.1 to $0.4 \mathrm{M}, 20-40 \mathrm{ml}$. per plant. The matorial usually drained down along the stem and came in contact with axillary buds. Within $30-60 \mathrm{~min}$ of such application the axillary buds had wilted and dried. Figs. $2 A$ and $B$ show the axillary buds of tobacco plants before and after treatment, respectively, with methyl caprate.

Intact tobacco plants with flower buds in early stage of development were also treated with methyl caprate in the same way as decapitated plants were. The development of flowers, of young top leaves, and of axillary buds was inhibited.

It appears that meristematic and differentiating young tissues are damaged when plants are treated with methyl ester, and that tissues in advanced stage of maturity are not affected. It is not clear whether the result is due to physical effects resulting from the change in surface tension of the cell membrane or to penetration of the compound into the young tissue and thus affecting the metabolic system.

T. C. Tso

Crops Research Division,

Agricultural Research Service,

U.S. Department of Agrieulture, Beltsville, Maryland.

${ }^{1}$ Hochster, R. M., and Quastel, J. H., Metabolic Inhibitors, 1, 154 (Academic Press, 1963).

${ }^{2}$ Tso, T. C., and McMurtrey, jum., J. E., Tob. Sci., 7, 101 (1963).

${ }^{3}$ Ahmed, K., and Scholefleld, P. G., Biochem. J., 81, 45 (1961).

\section{Carotenoid Pigments in a Mutant Strain of Verticillium albo-atrum Reinke and Berthold}

THE only pigment known to be produced by wild-type strains of $V$. albo-atrum is of a dark melanoid type ${ }^{1}$. In an investigation involving the production of biochemical mutants in this fungus (using a strain originally isolated from wilted lucerne, 1962), an orange pigmented colony, which had a partial requirement for biotin, developed on plates of complete medium spread with conidia irradiated with ultra-violet at a dosage allowing for approximately 5 per cent survival. The irradiation was carried out using a sterile distilled water suspension of conidia in an open Petri dish at a distance of $20 \mathrm{~cm}$ from a $2537 \AA$ 'Hanovia' bactericidal tube model 11 (with ozone reducing filter). The close resemblance of this colony.(designated $M .5$ ) in morphological details to wildtype led us to conclude that it is a mutant rather than a chance contaminant. The results of a preliminary extraction of $M .5$ suggested that several different carotenoids were present, and from further work, reported here, we have been able to identify some of these pigments.

Cultures of M.5 were grown on Wickerham's $M Y G P$ liquid medium ${ }^{2}$ on a reciprocating shaker at $20^{\circ} \mathrm{C}$, in the light. The pigments were extracted from 10-day-old cultures with methanol and transferred into diethyl ether by addition of water. The ethereal fraction was saponified ${ }^{3}$, freeze-dried and the pigments taken up in a small volume of $n$-hexane. This was then chromatographed on a magnesium oxide/'Celite' (1:1) column and development effeeted by washing with increasing concentrations of ether in $n$-hexane, and finally with acid methanol $(0.5$ per cent glacial acetic acid in methanol).

Ten fractions were separated out (Table 1). The colourless fraction 1 contained sterols (B. H. Davies, personal communication) and these were removed according to the method of Mercer et al. ${ }^{4}$. Phytoene was identified spectrophotometrically in this fraction and fractions $2,3,4,5$ and 10 identified as $\beta$-, $\gamma$-carotene, neo-lycopene A, lycopene and neurosporaxanthin. respectively. The

\begin{tabular}{|c|c|c|c|}
\hline Fraction & Appearance & $(\mathrm{m} \mu)$ in $n$-hexane & Probable nature \\
\hline 1 & Colourless & $\sim 277,291, \sim 303$ & Phvtoene \\
\hline 2 & Orange & $\sim 425,452, \quad 480$ & $\beta$-Carotene \\
\hline 3 & Orange & $435,460, \quad 490$ & $\gamma$-Carotene \\
\hline 4 & Retl-orange & 440,470 & Neo-lycopene $A$ \\
\hline 5 & $\begin{array}{l}\text { Red-pink } \\
\text { Blue }\end{array}$ & $\begin{array}{r}445,470, \quad 504 \\
\sim 460,480\end{array}$ & Lyeopenê \\
\hline 7 & Pink-orange & $\begin{array}{l}\sim 460,480, \sim 500 \\
\sim 445,478, \sim 502\end{array}$ & E \\
\hline 8 & Red & $\sim 450,482, \sim 505$ & - \\
\hline 9 & Red & $\sim 450,476, \quad 506$ & 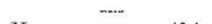 \\
\hline & Brown-orange & & oraxanthin \\
\hline
\end{tabular}

same extraction procedure was used for wild-typo cultures and only phytoene was found to be present.

The presence in $M .5$ of a number of different pigments which were not detectable in wild-type is, so far as we are aware, the first record of the simultaneous appearance of several carotenoid pigments in a hitherto colourless fungus. Several investigators, however, have reported changes in the balance and nature of carotenoids produced by mutant strains of coloured organisms, for example, in Neurospora crassa ${ }^{5}$, Rhodotorula rubra ${ }^{6}$, and Rhodopseudomonas spheroides ${ }^{7}$. The genetic basis for the enzyme system involved in carotenoid production must be already present in the wild-type and the result of the mutation in $M .5$ apparently serves as a 'trigger' to the synthesis of these pigments. It may be significant that phytoene, a colourless polyene thought to be a possible precursor of carotenoids $^{8}$, is present in both wild-type and mutant.

Conidia of $M .5$ were further irradiated with ultra. violet, and, as well as obtaining a range of coloured mutants which remain the subject for further investigation, a number of colourless revertants were produced. These revertants appear to have lost the ability to synthesize carotenoids but retain their partial requirements for biotin, and phytoene was again present. During this work it was noted that suspensions of $M .5$ conidia required irradiation for almost twice as long as those of wild-type to achieve the same 'killing effect' (5 per cent survival). This observation was confirmed when mixed suspensions of both types of conidia (that is, wild-type and $M .5$ ) were irradiated for varying periods and plated out on to complete medium. At the higher dosages only $M .5$ types developed. with the exception of a few colourless colonies which appeared with the same frequency as the revertants in parallel tests with $M .5$ alone. The difference in sensitivity to ultra-violet may be explained by the presence in $M .5$ of compounds which 'screen' the harmful effects of ultra-violet light. Further work will involve estimation of the relative proportions of ultra-violet absorbing substances such as ergosterol and phytoene shown to be present in conidia of both wild type and $M .5$.

Thanks are due to Dr. B. H. Davies for his advice on extraction procedure. This research has been aided by grants from the Central Research Fund of the University of London.

Botany Department,

Royal Holloway College

(University of London),

Englefield Green, Surrey.

L. R. G. VALADON

Biology Department.

Sir John Attkins Laboratories,

Queen Elizabeth College

(University of London),

Campden Hill, London, W.8.

${ }^{1}$ Heale, J. B., and Isaac, I., Nature, 202, 412 (1964).

${ }^{2}$ Wickerham, L. J., Tech. Bull. U.S. Dept. Agric., 1029, 1 (1951).

Goodwin, T. W., in Modern Methods of Plant Analysis, edit. by Paceh, K. and Tracey, M. V., 3, 282 (1955).

Mercer, E. I., Davies, B. H., and Goodwin, T. W., Biochem. J., 87. 317 (1963).

'Sheng, T. C., and Sheng, Ginger, Genetics, 37, 264 (1952).

'Bonner, J., Sandoval, A., Tang, Y. W., and Zeichmeister, L., Arrh. Biochem., io, 113 (1946).

7 Nakayama, T. O. M., Arch. Biochem. Biophys., 75, 356 (1958).

8 Davies, B. H., Jones, D., and Goodwin, T. W., Biochem. J., 87, 326 (1963). 